\title{
Development of Analytical Methods for Determination of $\beta$-Carotene in Pumpkin (Cucurbita maxima) Flesh, Peel, and Seed Powder Samples
}

\author{
Mulu Hagos, Mesfin Redi-Abshiro, Bhagwan Singh Chandravanshi $\mathbb{D}$, \\ and Estifanos Ele Yaya \\ Department of Chemistry, College of Natural and Computation Sciences, Addis Ababa University, P.O. Box 1176, \\ Addis Ababa, Ethiopia \\ Correspondence should be addressed to Bhagwan Singh Chandravanshi; bscv2006@yahoo.com
}

Received 14 November 2021; Revised 13 January 2022; Accepted 26 January 2022; Published 11 February 2022

Academic Editor: Valentina Venuti

Copyright (C) 2022 Mulu Hagos et al. This is an open access article distributed under the Creative Commons Attribution License, which permits unrestricted use, distribution, and reproduction in any medium, provided the original work is properly cited.

\begin{abstract}
Vegetables are consumed worldwide in fresh as well as processed forms. Pumpkin is considered as an important vegetable due to its nutritional values. The objective of this study was to evaluate all the analytical parameters and improve the performance of the methods for the determination of $\beta$-carotene in pumpkin flesh, peel, and seed samples using UV-VIS, NIR, and FTIR methods. $\beta$-Carotene was measured at $453 \mathrm{~nm}$ using the UV-VIS method which showed linear range, 0.1 to $12 \mu \mathrm{g} / \mathrm{mL} ; R^{2}, 0.999$; LOD, $0.034 \mu \mathrm{g} / \mathrm{mL}$; LOQ, $0.1 \mu \mathrm{g} / \mathrm{mL}$; RSD, $1.5 \%$ to $11 \%$; and percent recovery, $83 \%$ to $93 \%$. $\beta$-Carotene was also measured at $1415 \mathrm{~nm}$ using NIR and at $1710 \mathrm{~cm}^{-1}$ using FTIR spectroscopic methods. The NIR method exhibited linear range, 12.5 to $250 \mu \mathrm{g} / \mathrm{mL} ; R^{2}$, 0.999; LOD, $3.4 \mu \mathrm{g} / \mathrm{mL}$; LOQ, $10, \mu \mathrm{g} / \mathrm{mL}$; RSD, $1.8 \%$ to $11 \%$; and percent recovery, $92 \%$ to $96 \%$, while the FTIR method exhibited linear range, 4 to $100 \mu \mathrm{g} / \mathrm{mL} ; R^{2}$, 0.999; LOD, $1.3 \mu \mathrm{g} / \mathrm{mL}$; LOQ, $3.9 \mu \mathrm{g} / \mathrm{mL}$; RSD, $0.69 \%$ to $10 \%$; and percent recovery, $95 \%$ to $96 \%$. The characteristic analytical data indicated that any of the three newly developed methods could be used for the determination of $\beta$-carotene in the pumpkin flesh, peel, and seeds. Acetone was used as the extraction solvent for the UV-VIS and NIR spectroscopic methods, and acetonitrile was used as the extraction solvent for the FTIR method. Content of $\beta$-carotene was found higher in pumpkin peel (340-445 $\mu \mathrm{g} / \mathrm{g})$, followed by pumpkin flesh $(317-341 \mu \mathrm{g} / \mathrm{g})$ and pumpkin seed $(12-17 \mu \mathrm{g} / \mathrm{g})$ by the UV-VIS method. $\beta$-Carotene content was obtained $((376-451 \mu \mathrm{g} / \mathrm{g})$ and $(289-313 \mu \mathrm{g} / \mathrm{g}) ;(210-287 \mu \mathrm{g} / \mathrm{g})$ and $(102-148 \mu \mathrm{g} / \mathrm{g})) \mathrm{using}$ NIR and FTIR methods in pumpkin peel and flesh, respectively. $\beta$-Carotene was obtained higher from pumpkin peel by all the three methods than from pumpkin flesh and seed. The $\beta$-carotene content in the pumpkin seed was not detected by NIR and FTIR spectroscopic methods.
\end{abstract}

\section{Introduction}

Pumpkin is considered as an important vegetable crop due to its nutritional values. It is widely cultivated and consumed throughout the world. The most common species of pumpkin that are grown and used worldwide are Cucurbita maxima, Cucurbita pepo, and Cucurbita moschata $[1,2]$. The commonly consumed pumpkin species in Ethiopia is C. maxima (Figure 1). In Ethiopia, this vegetable is locally known as "Dubba". All parts of pumpkins are consumed without producing any waste. Every part of pumpkin are excellent sources of bioactive compounds like carotenoid, vitamins, minerals, fatty acids, carbohydrates, proteins, amino acids, volatile compounds, and phenolic compounds. It is believed that bioactive compounds of pumpkin have a protective role against many diseases, including hypertension, diabetes, and cancer and coronary heart diseases [3-8]. Despite these features, pumpkin is an under-utilized vegetable in Ethiopia.

One of the important components of pumpkin is $\beta$-carotene (Figure 2). It is a soluble plant pigment. $\beta$-Carotene is an important functional ingredient among the carotenoid compounds, due to its pro-vitamin A activity and its antioxidant action by scavenging oxygen radicals and 


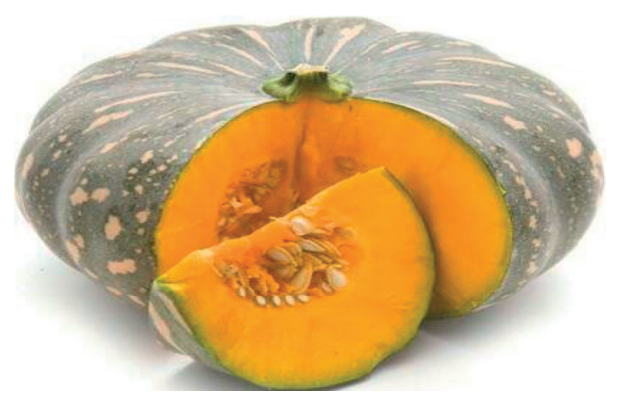

FIgUre 1: Pumpkin (Cucurbita maxima).

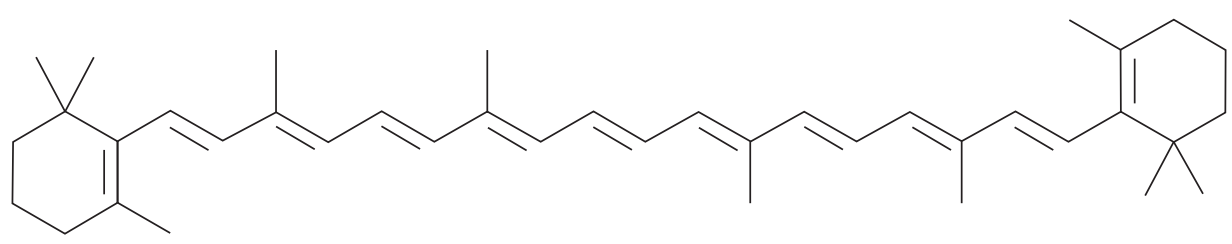

FIGURE 2: Structure of $\beta$-carotene.

reducing oxidative stress in the organism [6]. Consumption of $\beta$-carotene-rich food has the ability to increase the vitamin A intake among women and children who are always at risk of vitamin $\mathrm{A}$ deficiency [5]. In Ethiopia, vitamin $\mathrm{A}$ deficiency leads to 80,000 deaths in a year and affects $61 \%$ of preschool children [5]. The recommended daily intake of vitamin A is $900 \mathrm{mcg}$ for men, $700 \mathrm{mcg}$ for women, and 300 to $600 \mathrm{mcg}$ for children [8]. Consumption of pumpkin as a vegetable and/or processed food can be a good supplement of vitamin A for Ethiopians.

The $\beta$-carotene content in vegetables are influenced by many factors such as variety, level of maturity, climatic conditions, geographical location of production, part of the plant utilized, environmental conditions during agricultural production, postharvest handling, processing, storage conditions, and types of solvent used for the extraction. The $\beta$-carotene content in the pumpkin cultivated in different countries has been determined. However, to the best of our knowledge, there is no reported data on $\beta$-carotene content in any vegetable, including pumpkin (flesh, peel, and seeds) grown in Ethiopia.

Different analytical methods have been reported in the literature for the determination of $\beta$-carotene in fruits and vegetables. For quantitative analysis of carotenoids, UV-VIS spectrophotometry is the most convenient method [6, 8-12], by measuring the absorbance at different wavelengths. Highperformance liquid chromatographic (HPLC) methods [13-15] were reported for the identification and quantification of $\beta$-carotene in fruits and vegetables. For carotenoid evaluation, NIR spectroscopy in the wavelength region between 800 and $2500 \mathrm{~nm}$ were studied to evaluate $\beta$-carotene content $[12,16]$. The use of infrared spectroscopy in the study of $\beta$-carotene has also been reported. The development of Fourier transform infrared (FTIR) spectroscopy that operates in the mid-infrared region $\left(4000-400 \mathrm{~cm}^{-1}\right)$ has been proven to be a powerful tool for quantitative determination of $\beta$-carotene $[12,16-19]$. Each of these methods has its own advantages and limitations. The researchers are still investigating to develop simple, fast, sensitive, and selective methods for the determination of $\beta$-carotene in different vegetables. Hence, the objective of the present research work was to evaluate all the analytical parameters to improve the performance of UV-VIS, NIR, and FTIR methods to determine $\beta$-carotene content in three parts of the pumpkin flesh, peel, and seed samples.

\section{Materials and Methods}

2.1. Instruments and Apparatus. Samples were weighed using electronic balance (ARA520, OHAUS CORP, China). Blending device mortar and pestle was used to ground the dried pumpkin samples. Centrifuge machine (800D, China), double-beam spectrophotometer (Lambda 950-UV-VisNIR, Perkin Elmer, UK) interfaced with a computer using $2 \mathrm{~nm}$ resolution in a $1 \mathrm{~cm}$ path length quartz cell and FTIR spectrometer (Perkin Elmer Spectrum 65 Spectrophotometer, USA) with a sample holder of zinc selenide crystal in the attenuated total reflectance (ATR) mode were used for determination of $\beta$-carotene.

2.2. Chemicals. Dichloromethane (ACS ISO-Reagent, European Pharmacopoeia, 99.9\%), acetone (ACS ISO-Reagent, European Pharmacopoeia, 99.8\%), methanol (Jeulin, France, 99.5\%), acetonitrile (Scharlau Chemie SA, Spain, 99.7\%), and cyclohexane (Fisher Chemical, UK, 99\%) were used for extraction of $\beta$-carotene. Pumpkin samples were collected from Dukem and Debre Berhan (Ethiopia). $\beta$-Carotene standard (Sigma-Aldrich, 99\%) were obtained from Ethiopian Public Health Institute.

2.3. Preparation of $\beta$-Carotene Standard Solutions for the UVVIS Method. A $15 \mu \mathrm{g} / \mathrm{mL}$ standard stock solution of $\beta$-carotene was prepared by dissolving $750 \mu \mathrm{g}$ of the standard $\beta$-carotene in $50 \mathrm{~mL}$ volumetric flask in acetone. From this stock solution, serial dilutions were made to obtain $0.1,0.5$, $1.5,3,6,9$, and $12 \mu \mathrm{g} / \mathrm{mL}$ of $\beta$-carotene. The working 
standard solutions were scanned in the spectral range (350-600 nm) selected for this study. The absorption spectral data were collected from their typical absorption peak maximum obtained at $453 \mathrm{~nm}$ for plotting the calibration curves.

2.4. Preparation of $\beta$-Carotene Standard Solutions for the NIR Spectroscopic Method. A $250 \mu \mathrm{g} / \mathrm{mL}$ standard stock solution of $\beta$-carotene was prepared by dissolving $12,500 \mu \mathrm{g}$ of the standard $\beta$-carotene in $50 \mathrm{~mL}$ volumetric flask in acetone. From this stock solution, serial dilutions were made to obtain $12.5,20,35,60,100,160,190$, and $250 \mu \mathrm{g} / \mathrm{mL}$ of $\beta$-carotene. The working standard solutions were scanned in the spectral range $(1000-1600 \mathrm{~nm})$ selected for this study. The absorption spectral data were collected from their typical absorption peak maximum obtained at $1415 \mathrm{~nm}$ for plotting the calibration curves.

2.5. Preparation of $\beta$-Carotene Standard Solutions for the FTIR Spectroscopic Method. A $100 \mu \mathrm{g} / \mathrm{mL}$ standard stock solution of $\beta$-carotene was prepared by dissolving $5000 \mu \mathrm{g}$ of the standard $\beta$-carotene in $50 \mathrm{~mL}$ volumetric flask in acetonitrile. From this stock solution, serial dilutions were made to obtain $4,8,12,23,55$, and $100 \mu \mathrm{g} / \mathrm{mL}$ of $\beta$-carotene. About $1 \mathrm{~mL}$ of the standard solution was placed in the zinc selenide crystal to fully cover its surface for the spectral measurements. The working standard solutions were scanned in the spectral range $\left(1000-4000 \mathrm{~cm}^{-1}\right)$ selected for this study. The absorption spectral data were collected from their typical absorption peak maximum obtained at $1500-2000 \mathrm{~cm}^{-1}$ for plotting the calibration curves.

2.6. Preparation of Pumpkin Peel, Flesh, and Seed Powder Samples. Pumpkin samples were washed with fresh running water and then with distilled water to remove any foreign materials attached. The separation of the three parts (peel, flesh, and seed) of the pumpkin was done manually with the help of a knife. The three parts of the pumpkin samples were cut in to small pieces and dried at room temperature for 1 week. The dried samples were ground with mortar and pestle. Finally, the powdered samples were used for the extraction of $\beta$-carotene.

2.7. Extractions of $\beta$-Carotene. $\beta$-Carotene extraction was done according to the method reported by Barba et al. [11] with some modifications. The $\beta$-carotene was extracted by soaking $0.5 \mathrm{~g}$ of samples for UV-VIS and $5.0 \mathrm{~g}$ of samples for NIR and FTIR in $25 \mathrm{~mL}$ of different solvents (dichloromethane, acetone, methanol, acetonitrile, and cyclohexane) at room temperature under dark condition in order to get a complete extraction. The mixture was magnetically stirred for $30 \mathrm{~min}$. The extracts were centrifuged to separate the supernatant, and these operations were repeated until the pulp was completely colorless. The volume was made up to $50 \mathrm{~mL}$ with the extracting solvents. Finally, the absorbance of the extracts was measured using UV-VIS, NIR, and FTIR methods.
2.8. Method Validation. Method validation was evaluated in terms of linearity, accuracy, precision, limits of detection (LOD), and quantitation (LOQ). Linearity of the method was performed in a range of 0.1 to $12 \mu \mathrm{g} / \mathrm{mL}$ for UV-VIS, 12.5 to $250 \mu \mathrm{g} / \mathrm{mL}$ for NIR, and 4 to $100 \mu \mathrm{g} / \mathrm{mL}$ for FTIR methods and correlation coefficients $\left(R^{2}\right)$ were evaluated. Precision was determined from repeatability, intraday, and interday precision, and relative standard deviation (RDS) was calculated. Repeatability was from repetitive UV-VIS, NIR, and FTIR measurement of standard $\beta$-carotene solution $(n=6)$. Intraday precision was determined on the same day $(n=3)$, and interday precision was determined on different days $(n=3)$. Accuracy was estimated by the standard addition method, and recovery $(\% R)$ was calculated. Standard $\beta$-carotene solution was added into the sample, and absorption of the spiked and unspiked samples was measured. The recovery $(\% R)$ was calculated using the formula (amount found/amount added) $\times 100$. LOD and LOQ were calculated from $(3 \times \mathrm{SD}) / s$ and $(10 \times \mathrm{SD}) / s$, where SD and $s$ were standard deviation of blank measurement $(n=6)$ and slope of calibration curve, respectively.

\section{Results and Discussion}

3.1. Extraction Solvent Optimization. To obtain the best extraction efficiency, different extraction solvents were optimized. Five extraction solvents (dichloromethane, acetone, methanol, acetonitrile, and cyclohexane) were used to compare the extraction efficiency of $\beta$-carotene from pumpkin flesh, peel, and seed. Better extraction efficiency of $\beta$-carotene was observed when using acetone than the other extraction solvents, as determined by UV-VIS absorption analysis. Cyclohexane extraction resulted in lower extraction efficiency than the other extraction solvents (Figure 3). Therefore, acetone was selected as a solvent for the extraction of $\beta$-carotene for further analysis in this study.

\subsection{Determination of $\beta$-Carotene in Pumpkin Peel, Flesh, and Seed Using the UV-VIS Method}

3.2.1. Identification. The UV-VIS spectrum of $\beta$-carotene in acetone was scanned from 350 to $600 \mathrm{~nm}$, and maximum absorption was obtained at $453 \mathrm{~nm}$. This was in good agreement with that reported in literature $[6,8,11-13]$. The UV-VIS spectra of pumpkin flesh and peel extracts showed the maximum UV-VIS absorption at the same wavelength (Figure 4). This confirmed that the extraction procedure was valid and the extract contained $\beta$-carotene. In the case of pumpkin seed, the extract showed the maximum UV-VIS absorption at $440 \mathrm{~nm}$ (Figure 4). The shift in absorption maximum and curve shape may be attributed to the different chemical environment in the seed as compared to the flesh and peel. The good selectivity of the newly developed UV-VIS method is evidenced by an overlapping standard and sample spectra, which clearly indicates the reduction of the matrix interference to a negligible levels. 


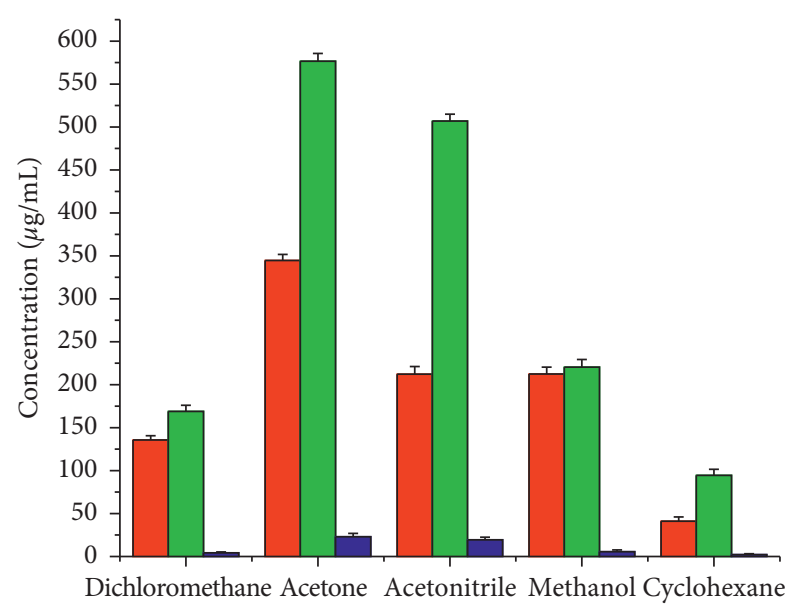

Organic solvents

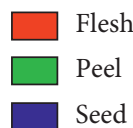

Figure 3: Results of efficiency of five extraction solvents (dichloromethane, acetone, methanol, acetonitrile, and cyclohexane) in pumpkin flesh, peel, and seed samples based on UV-VIS absorption analysis.

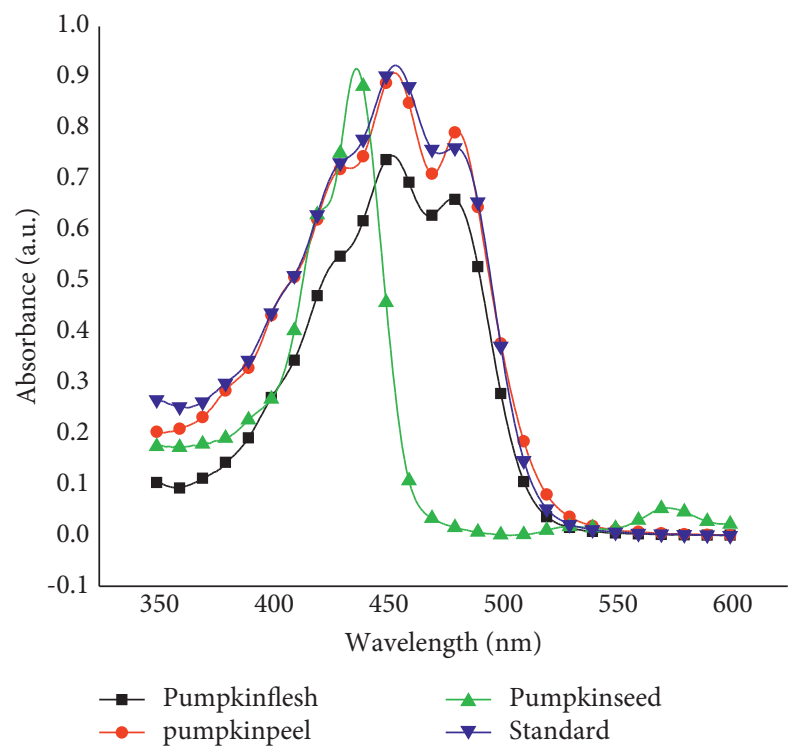

FIGURE 4: UV-VIS spectra of standard $\beta$-carotene and $\beta$-carotene extracts from pumpkin flesh, peel, and seed samples.

3.2.2. Method Validation for UV-VIS. Linearity of the method was performed in a range of 0.1 to $12 \mu \mathrm{g} / \mathrm{mL}$, and the method showed good linearity with a regression of $y=0.25566 x-0.0049\left(R^{2}=0.999\right)$ (Figure 5). In addition, both the detection limit and quantification limit were calculated to be $0.034 \mu \mathrm{g} / \mathrm{mL}$ and $0.1 \mu \mathrm{g} / \mathrm{mL}$, respectively. Method repeatability showed RSD\% of $1.5 \%$. Intraday and interday precision were RSD $1.8 \%$ to $2.8 \%$ and $3.7 \%$ to $11 \%$, respectively. Method accuracy was evaluated by standard addition to the sample, and the results obtained showed good percent recovery $(\% R)$ of $83 \%$ to $93 \%$.
3.2.3. UV-VIS Method for Real Sample Analysis. The developed UV-VIS method was applied for the determination of $\beta$-carotene content in the acetone extract of the pumpkin peel, flesh, and seeds samples. $\beta$-Carotene content in the sample $(\mu \mathrm{g} / \mathrm{g})$ was calculated using calibration curve. The results are given in Table 1 . Content of $\beta$-carotene was obtained higher amount in pumpkin peel followed by pumpkin flesh and pumpkin seed samples (Table 1).

\subsection{Determination of $\beta$-Carotene in Pumpkin Flesh, Peel, and Seed Samples Using the NIR Spectroscopic Method}

3.3.1. Identification. The NIR spectra of $\beta$-carotene in acetone were scanned from 1000 to $1600 \mathrm{~nm}$ spectral range, and maximum absorption was obtained at $1415 \mathrm{~nm}$, which is attributed to the first overtone band of $\mathrm{C}-\mathrm{H}$ stretching mode. This was in good agreement with that reported by Nokkaew et al. and Rungpichayapichet et al. [20, 21]. NIR spectra of pumpkin flesh and peel extract revealed maximum NIR absorption at the same wavelength, that is, at $1415 \mathrm{~nm}$ (Figure 6). This confirmed that the extraction procedure was valid and the extract contained $\beta$-carotene. The perfectly overlapping standard and sample spectra clearly indicate the reduction of the matrix interference to a negligible levels. Furthermore, this also demonstrates the excellent selectivity of the newly developed NIR method.

3.3.2. Method Validation for NIR Spectroscopy. Linearity of the method was performed in concentration range between 12.5 and $250 \mu \mathrm{g} / \mathrm{mL}$, and the method showed good linearity with regression equation of $y=0.0001688+0.0012 x$ and regression coefficient of $R^{2}=0.99994$ (Figure 7). In addition, both detection limit and quantification limit were calculated to be $3.4 \mu \mathrm{g} / \mathrm{mL}$ and $10 \mu \mathrm{g} / \mathrm{mL}$, respectively. Method repeatability showed RSD of $3.7 \%$. Intraday and interday precision were RSD in ranges of $1.8 \%$ to $3.5 \%$ and $4.9 \%$ to $11 \%$, respectively. Method accuracy was evaluated by standard addition to the sample, and the results obtained showed good percent recovery (\%R) of $92.0 \%$ to $96.0 \%$.

3.3.3. NIR Spectroscopic Method for Real Sample Analysis. The content of $\beta$-carotene in pumpkin (flesh, peel, and seed) samples was determined by NIR spectroscopic method. The content of $\beta$-carotene $(\mu \mathrm{g} / \mathrm{g})$ was calculated using the calibration curve. Content of $\beta$-carotene was obtained higher in pumpkin peel, followed by pumpkin flesh. The $\beta$-carotene content in pumpkin seed was not detected in NIR spectroscopic method (Table 2).

\subsection{Determination of $\beta$-Carotene Content in Pumpkin Flesh, Peel, and Seed Samples Using the FTIR Spectroscopic Method}

3.4.1. Identification. New FTIR method was developed for quantitation of $\beta$-carotene in pumpkin peel, flesh, and seed samples using a liquid sampling technique. In order to choose an appropriate solvent for the analysis, pure $\beta$-carotene was 

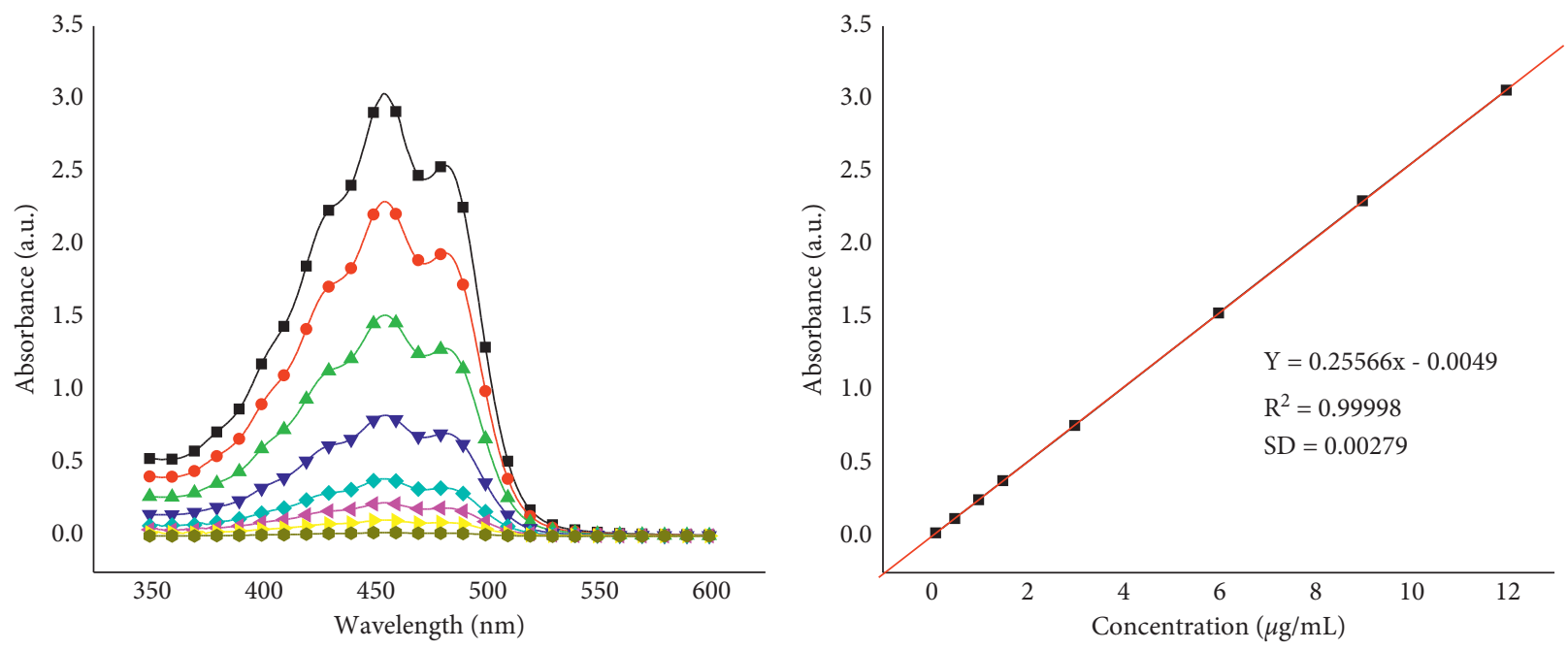

Conc. $\mu \mathrm{g} / \mathrm{mL}$

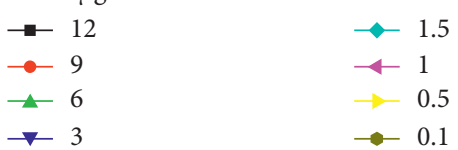

(a) (b)

(a) and calibration curve (b).

TABLE 1: Content $(\mu \mathrm{g} / \mathrm{g})$ of $\beta$-carotene from the three parts of pumpkin, namely, peel, flesh, and seed samples using the UV-VIS method.

\begin{tabular}{|c|c|c|c|}
\hline \multirow{2}{*}{ Sample area } & \multicolumn{3}{|c|}{$\beta$-Carotene in pumpkin $(\mu \mathrm{g} / \mathrm{g})$} \\
\hline & Flesh & Peel & Seed \\
\hline Dukem & 341 & 445 & 17 \\
\hline Debre Berhan & 317 & 340 & 12 \\
\hline
\end{tabular}

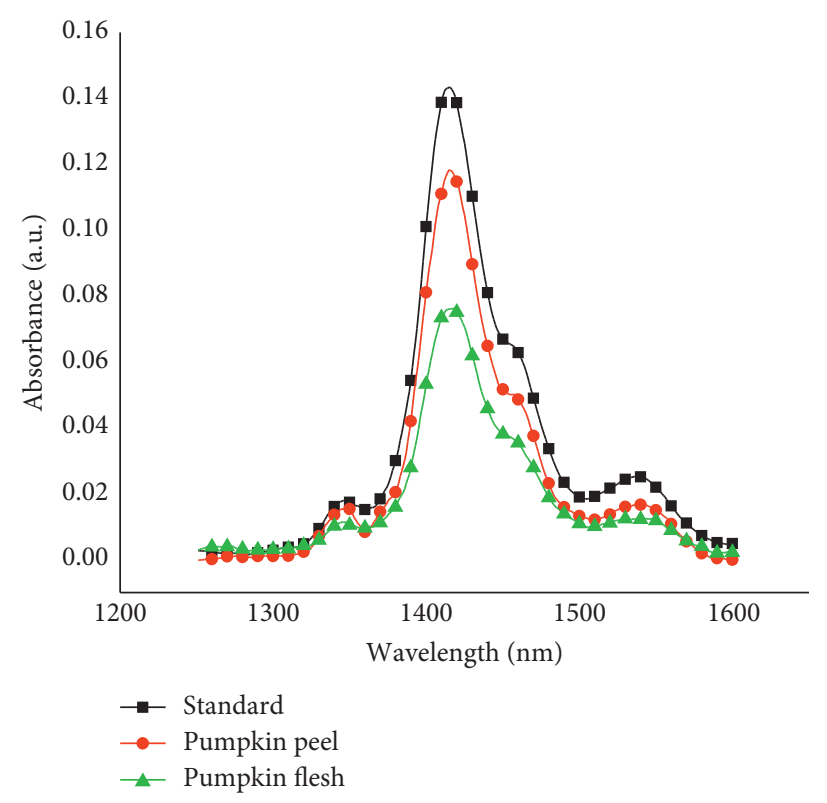

FIGURE 6: NIR spectra of standard $\beta$-carotene and $\beta$-carotene from pumpkin flesh and peel with acetone extracts. 

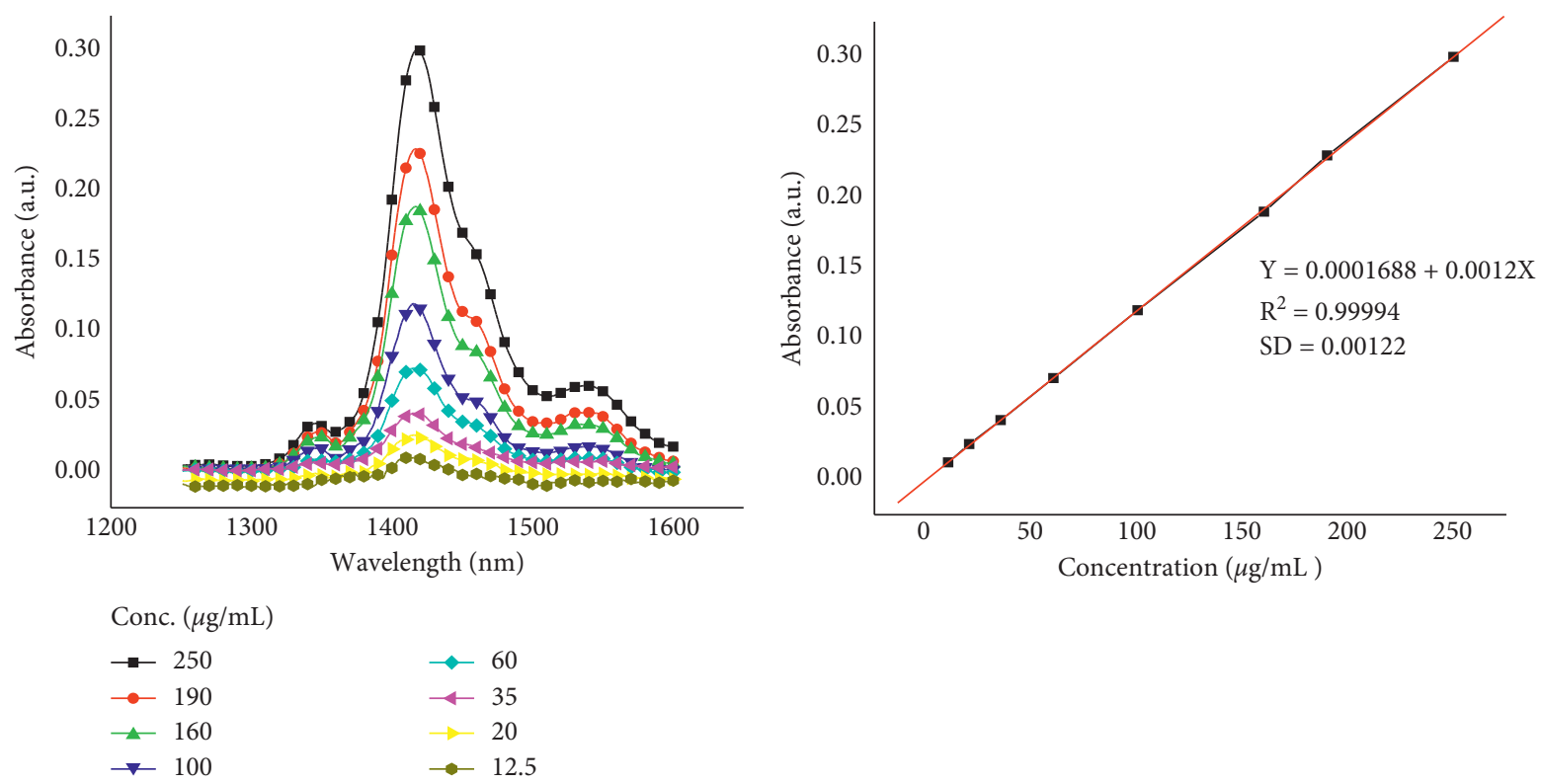

(a)

(b)

FIgURE 7: NIR spectra of different standard concentrations of $\beta$-carotene (a) and calibration curve (b).

TABLE 2: Content $(\mu \mathrm{g} / \mathrm{g})$ of $\beta$-carotene from the three parts of pumpkin (peel, flesh, and seed) samples using the NIR spectroscopic method.

\begin{tabular}{lccc}
\hline Sample area & & $\beta$-Carotene in pumpkin $(\mu \mathrm{g} / \mathrm{g})$ & \\
& Flesh & Peel & Seed \\
\hline Dukem & 313 & 451 & ND \\
Debre Berhan & 289 & 376 & ND \\
\hline
\end{tabular}

$\mathrm{ND}=$ not detected.

dissolved in three different solvents (acetone, methanol, and acetonitrile) and FTIR spectra were recorded (Figure 8).

The absorption bands from 2900 to $3050 \mathrm{~cm}^{-1}$ were the common asymmetric and symmetric stretching modes of the $\mathrm{C}-\mathrm{H}$ groups. The weak absorption band observed at $3005 \mathrm{~cm}^{-1}$ is due to the trans $-\mathrm{CH}=\mathrm{CH}$ of the $\beta$-carotene. The sharp band at $1462 \mathrm{~cm}^{-1}$ arose from the asymmetric deformation mode, whereas the band at $1360 \mathrm{~cm}^{-1}$ was the symmetric deformation mode of the $\mathrm{C}-\mathrm{H}$ group. The peak around 1500 to $2000 \mathrm{~cm}^{-1}$ corresponds to $\mathrm{C}=\mathrm{C}$ double bond stretching vibrations of $\beta$-carotene. For quantitative analysis, the intensities in the spectral region 1500 to $2000 \mathrm{~cm}^{-1}$ were chosen because the peak at $1710 \mathrm{~cm}^{-1}$ have strong intensity in the pure $\beta$-carotene as well as in the given samples, and thus the wavenumber $\left(\mathrm{cm}^{-1}\right) 1710 \mathrm{~cm}^{-1}$ was chosen for the quantification propose. However, $\beta$-carotene spectra in acetone and methanol solvents indicated some interfering absorption bands of the solvent itself at around $1710 \mathrm{~cm}^{-1}$. Due to this reason, acetonitrile was selected to be an appropriate solvent. FTIR spectrum of $\beta$-carotene in acetonitrile was scanned from 1500 to $2000 \mathrm{~cm}^{-1}$, and maximum absorption was obtained at $1710 \mathrm{~cm}^{-1}$ which is due to the $\mathrm{C}=\mathrm{C}$ stretching vibrational mode.

Subsequently, FTIR spectra of pumpkin flesh and peel extracts were recorded and showed maximum absorption at the same wavenumber (Figure 9). This confirmed that the extraction procedure was valid and the extract contained $\beta$-carotene. The overlapping of standard and sample spectra clearly indicates the reduction of the matrix interference to a negligible level. Furthermore, this also demonstrates the good selectivity of the newly developed FTIR method.

\subsubsection{Method Validation for FTIR Spectroscopy.} Linearity of the method was performed in a concentration range between 4 and $100 \mu \mathrm{g} / \mathrm{mL}$. The method showed good linearity with regression equation of $y=0.00414+0.02602 x$ and regression coefficient $R^{2}=0.99995$ (Figure 10). In addition, both detection limit and quantification limit were $1.3 \mu \mathrm{g} / \mathrm{mL}$ and $3.9 \mu \mathrm{g} / \mathrm{mL}$, respectively. Method repeatability showed RSD of $0.95 \%$. Intraday and interday precision revealed $\mathrm{RSD}$ of $0.69 \%$ to $5.6 \%$ and $3.9 \%$ to $10 \%$, respectively. Method accuracy was evaluated by standard addition to the sample and the results obtained showed good percent recovery $(\% R)$ of $95 \%$ to $96 \%$.

3.4.3. FTIR Method for Real Sample Analysis. The content of $\beta$-carotene in the pumpkin flesh, peel, and seed sample was determined by FTIR spectroscopic method. The $\beta$-carotene content $(\mu \mathrm{g} / \mathrm{g})$ was calculated using calibration curve. Content of $\beta$-carotene was obtained higher in pumpkin peel, followed by pumpkin flesh. The $\beta$-carotene content in pumpkin seed was not detected using FTIR spectroscopic method (Table 3 ). 


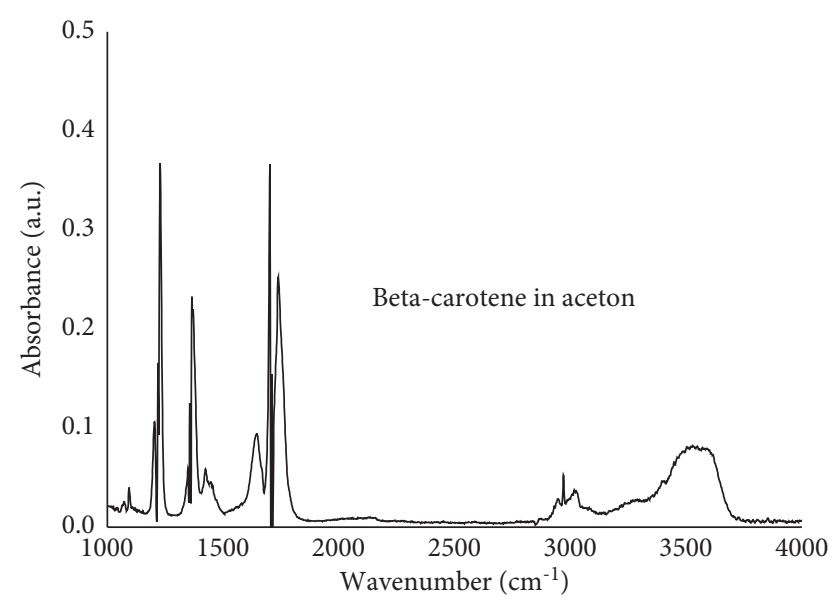

(a)

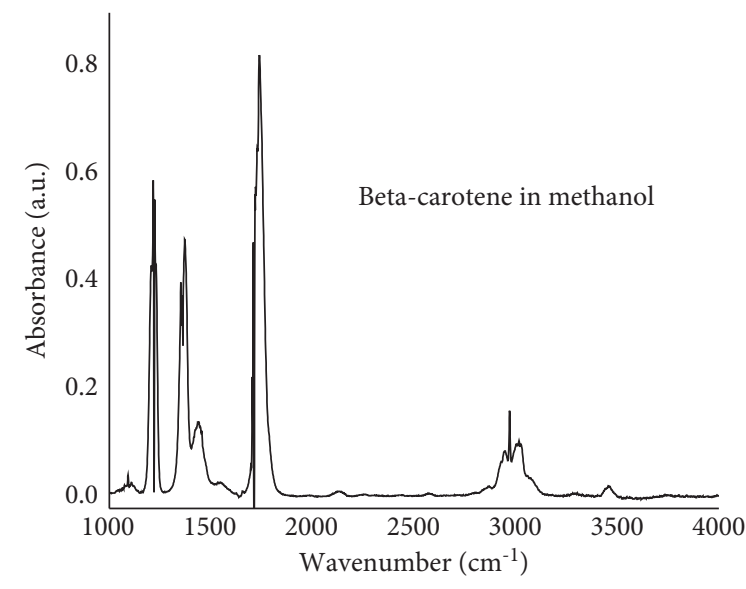

(b)

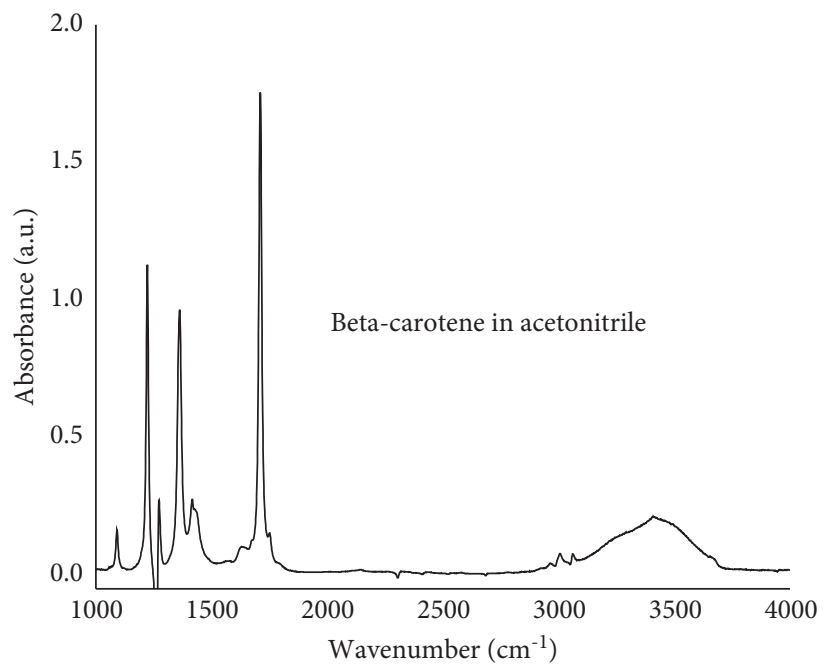

(c)

FIGURE 8: FTIR-ATR spectra of $\beta$-carotene in acetone (a), methanol (b), and acetonitrile (c).

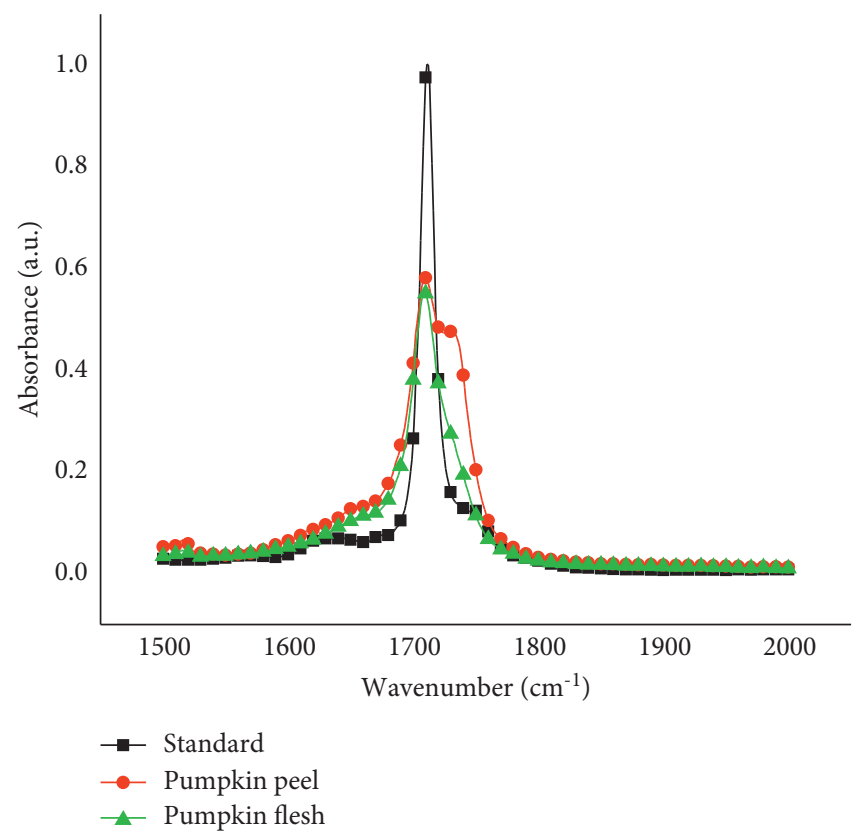

FIGURE 9: FTIR spectra of standard $\beta$-carotene and $\beta$-carotene from pumpkin flesh and peel in acetonitrile extracts. 


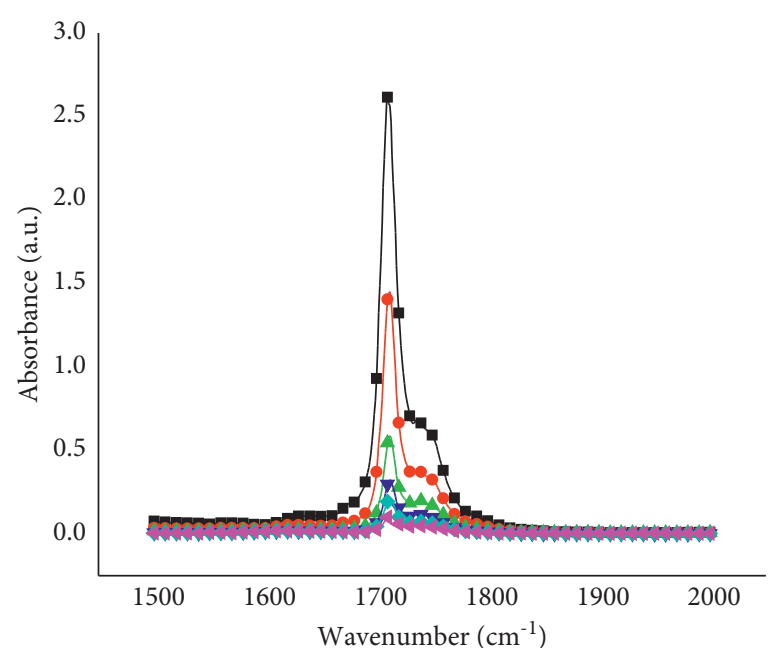

Conc. $(\mu \mathrm{g} / \mathrm{mL})$

$\rightarrow 100$

$\rightarrow 55$

$\rightarrow 23$

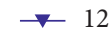

$\rightarrow-8$

$-4$

(a)

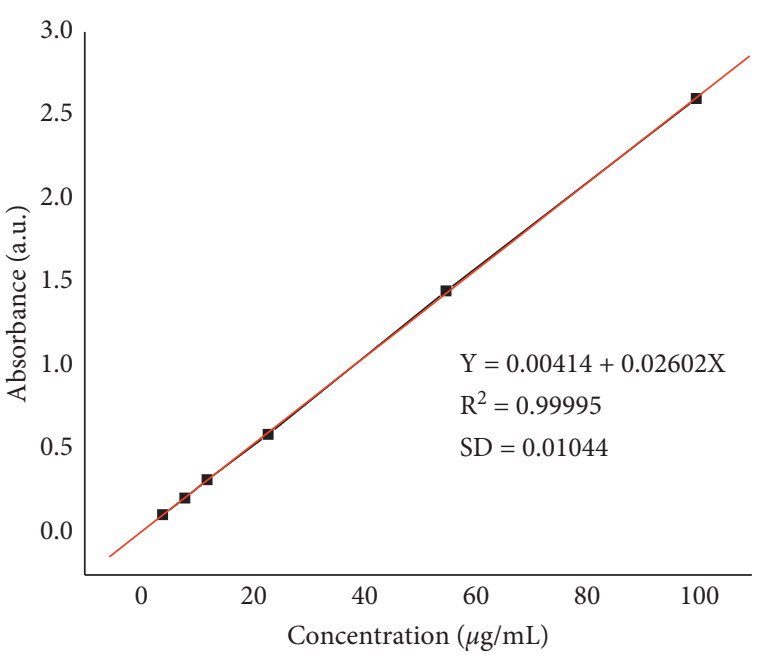

(b)

FIGURE 10: FTIR spectra of different concentrations of standard $\beta$-carotene in acetonitrile (a) and calibration plot (b).

TABLE 3: Content $(\mu \mathrm{g} / \mathrm{g})$ of $\beta$-carotene in the pumpkin peel, flesh, and seed samples using the FTIR spectroscopic method.

\begin{tabular}{lccc}
\hline \multirow{2}{*}{ Sample area } & \multicolumn{3}{c}{$\beta$-Carotene in pumpkin $(\mu \mathrm{g} / \mathrm{g})$} \\
& Flesh & Peel & Seed \\
\hline Dukem & 210 & 287 & ND \\
Debre Berhan & 102 & 148 & ND \\
\hline
\end{tabular}

$\mathrm{ND}=$ not detected.

3.5. Comparison of Results Obtained by Three Developed Methods for $\beta$-Carotene Determination. In this study, three different methods were developed for the quantitative determination of $\beta$-carotene in the pumpkin flesh, peel, and seed by using acetone and acetonitrile as the extraction solvents. The analytical parameters such as correlation coefficient $\left(R^{2}\right)$, linear range, limit of detection (LOD), limit of quantification (LOQ), and relative standard deviation (RSD) obtained by the newly developed UV-VIS method are in good agreement with results reported by Karnjanawipagul et al. [7], and analytical parameters obtained in this study are better than results reported by Biswas et al. [22] (Table 4). Some of the analytical parameters such as limit of detection (LOD) and limit of quantification (LOQ) of the method were not reported by Biswas et al. [22].

The analytical parameters for NIR and FTIR methods were not reported except correlation coefficient $\left(R^{2}\right)$ in the literature methods for NIR $[23,24]$ and for FTIR methods $[16,25]$.

Since, the objective of the present research work was to improve the performance of analytical methods (UV-VIS, NIR, and FTIR) to determine $\beta$-carotene content in three parts of pumpkin flesh, peel, and seed samples, all the analytical parameters such as correlation coefficient $\left(R^{2}\right)$, linear range, limit of detection (LOD), limit of quantification
(LOQ), recoveries $(\% R)$, and relative standard deviation (\% RSD) have been evaluated and reported for the newly developed (UV-VIS, NIR, and FTIR) methods. The three newly developed methods are applicable to determine $\beta$-carotene with good linearity, precision, accuracy, and sensitivity in the three parts of pumpkin. Thus, the developed methods indicate better performance than previously published methods (Table 4).

Some of these RSD\% values were slightly higher because $\beta$-carotene was unstable and easily degraded at room temperature. However, they were in acceptable ranges according to AOAC [26] regulation. Validation data indicated that the developed methods showed good linearity, precision, accuracy, and sensitivity, which could be used for the determination of $\beta$-carotene in pumpkin flesh, peel, and seed samples.

3.6. Comparison of Results Obtained by the Present Developed Methods with Literature-Reported Methods. In this study, $\beta$-carotene content was obtained in the range of 317 to 341 , 340 to 445 , and 12 to $17 \mu \mathrm{g} / \mathrm{g}$ in pumpkin flesh, peel, and seed using UV-VIS method; 289 to 313 and 376 to $451 \mu \mathrm{g} / \mathrm{g}$ in pumpkin flesh and peel using NIR method; 102 to 148 and 210 to $287 \mu \mathrm{g} / \mathrm{g}$ in pumpkin flesh and peel using FTIR method. $\beta$-Carotene was not detected in pumpkin seed using NIR and FTIR methods.

To further validate the developed methods, it is necessary to compare the results with literature-reported methods such as UV-VIS, NIR, FTIR, and HPLC. There are different reported ranges of $\beta$-carotene content of different vegetables including pumpkin flesh, peel, and seed. In a study with pumpkin (C. moschata) flesh, $\beta$-carotene content varied between 168 and $202 \mu \mathrm{g} / \mathrm{g}$ [10]. Carotenoids determination 
TABLE 4: Analytical parameters of the proposed methods such as $R^{2}$, LODs, LOQs, RSDs, and recoveries compared with the previously published methods.

\begin{tabular}{lccccccc}
\hline Methods & Linearity range $(\mu \mathrm{g} / \mathrm{mL})$ & $R^{2}$ & LOD $(\mu \mathrm{g} / \mathrm{mL})$ & LOQ $(\mu \mathrm{g} / \mathrm{mL})$ & RSD $(\%)$ & Recovery $(\%)$ & Reference \\
\hline UV-VIS & $0.1-12.0$ & 0.999 & 0.034 & 0.10 & $1.5-11$ & $83-93$ & This study \\
UV-VIS & $1-8$ & 0.999 & 0.04 & 0.11 & 6.4 & 100 & {$[7]$} \\
UV-VIS & $0.015-8$ & 0.994 & NR & NR & $3.4-8.9$ & $67.8-98.8$ & {$[22]$} \\
NIR & $12.5-250$ & 0.999 & 3.400 & 10.2 & $1.8-11$ & $92-96$ & This study \\
NIR & $0-24$ & 0.81 & NR & NR & NR & NR \\
NIR & $2.3-28$ & 0.81 & NR & NR & NR & NR & {$[23]$} \\
FTIR & $4-100$ & 0.999 & 1.320 & 3.97 & $0.7-10$ & $95-96$ & This study \\
FTIR & $1.8-6.6$ & 0.91 & NR & NR & NR & NR & NR \\
FTIR & $183-2137$ & 0.95 & NR & NR & NR & NR & {$[16]$} \\
\hline
\end{tabular}

$\mathrm{NR}=$ not reported.

TABLE 5: Comparison of $\beta$-carotene content in the pumpkin flesh, peel, and seed samples obtained by three newly developed methods with the values reported in the literature methods.

\begin{tabular}{lcccc}
\hline Methods & & $\beta$-Carotene in pumpkin $(\mu \mathrm{g} / \mathrm{g})$ & & Seed \\
\hline UV-VIS & Flesh & Peel & $12-17$ & Reference \\
NIR & $317-341$ & $340-445$ & ND & This study \\
FTIR & $289-313$ & $376-451$ & ND & This study \\
UV-VIS & $102-210$ & $148-287$ & - & This study \\
FTIR & $168-202$ & - & - & {$[10]$} \\
HPLC & $156-2137$ & - & 17 & {$[16]$} \\
HPLC & $17-263$ & $10-403$ & - & {$[15]$} \\
HPLC & 31 & - & $123]$ & {$[29]$} \\
\hline
\end{tabular}

TABLE 6: $\beta$-Carotene content $(\mu \mathrm{g} / \mathrm{g})$ of the same pumpkin flesh using different methods.

\begin{tabular}{lc}
\hline \multicolumn{2}{c}{ Comparison of results of the two newly developed UV-VIS and FTIR methods } \\
\hline UV-VIS & FTIR \\
\hline $202 \mu \mathrm{g} / \mathrm{g}$ & $198 \mu \mathrm{g} / \mathrm{g}$ \\
\hline Comparison of results of the newly developed method with published method [30] & \\
\hline Present UV-VIS & UV-VIS published method [30] \\
\hline $202 \mu \mathrm{g} / \mathrm{g}$ & $204 \mu \mathrm{g} / \mathrm{g}$ \\
\hline
\end{tabular}

in pumpkin flesh content varied between 156 and $2137 \mu \mathrm{g} / \mathrm{g}$ [16]. The investigation performed in crude palm oil reported in the range of 260 to $783 \mu \mathrm{g} / \mathrm{g}$ [12].

In the investigation performed in pumpkin (C. maxima) flesh and peel using HPLC-DAD method, $\beta$-carotene content ranged from 17 to $263 \mu \mathrm{g} / \mathrm{g}$ in flesh and 10 to $403 \mu \mathrm{g} / \mathrm{g}$ in peel [15]. Kim et al. [27] reported the determination of different carotenoids in pumpkin (C. maxima) flesh, peel, and seed, the content of $\beta$-carotene were obtained $17 \mu \mathrm{g} / \mathrm{g}$ in flesh, $123 \mu \mathrm{g} / \mathrm{g}$ in peel, and $31 \mu \mathrm{g} / \mathrm{g}$ in seed powder samples. Pongjanta et al. [28] prepared pumpkin powder to utilize it in different bakery products and made a comparison of $\beta$-carotene in fresh pumpkin and pumpkin powder. The amount of $\beta$-carotene reported in fresh and powder pumpkin were $24 \mu \mathrm{g} / \mathrm{g}$ and $73 \mu \mathrm{g} / \mathrm{g}$, respectively. Nakazibwe et al. [29] also reported $\beta$-carotene content 27 to $1215 \mu \mathrm{g} / \mathrm{g}$ in three variety of pumpkin flesh samples (Table 5 ).

In this study, $\beta$-carotene content was determined in the three parts of pumpkin namely flesh, peel, and seed, collected from two different sample area (Dukem and Debre Berhan) of Ethiopia. The variation in $\beta$-carotene content observed in the three newly developed methods may be attributed to the difference in the origin and ripping stages of the pumpkin samples. Therefore, to make the comparison meaningful, we have conducted the experiments on the same pumpkin samples by the FTIR-ATR and UV-VIS methods, and the results obtained by the two newly developed methods are in good agreement. The results are given in Table 6.

We have conducted further experiment to determine $\beta$-carotene content in the pumpkin flesh by a literaturereported UV/VIS spectrophotometric method [30]. The results obtained on the $\beta$-carotene content in the pumpkin flesh by the newly developed UV/VIS spectrophotometric method are comparable with the literature-reported method [30]. The results are given in Table 6 , which demonstrate the validation of the newly developed method.

The variation in the content of $\beta$-carotene in three parts of pumpkin flesh, peel, and seed may be due to the presence of different chemical compositions. Kim et al. [27] reported that $\beta$-carotene concentration in three species of pumpkin such as C. pepo, C. moschata, and C. maxima are found to be 
high in peels compared to flesh and seeds. Generally, results obtained in this study are comparable with the results literature reported using UV-VIS spectrophotometry [10], FTIR [12, 16], and HPLC [15, 27-29] methods (Table 5). It should be noted that the pumpkin sample used in the FTIRATR method was different from that used in the UV-VIS and NIR methods. As the $\beta$-carotene content in the pumpkin sample depends on the origin and maturity of the fruit and as two different fruits were used for the FTIR-ATR method and UV-VIS and NIR methods, the results of $\beta$-carotene content in the two pumpkin samples were different. To make the comparison meaning, we have conducted the experiments on the same pumpkin samples, and the results obtained by the three newly developed methods are in good agreement. The new results are included in Table 6 .

\section{Conclusion}

This study evaluated all the analytical parameters and demonstrated improvement in the performance of the analytical methods for the determination of $\beta$-carotene in pumpkin flesh, peel, and seed samples using UV-VIS, NIR, and FTIR methods. All the three methods are applicable to determine $\beta$-carotene content in pumpkin with good linearity, precision, accuracy, and sensitivity. The content of $\beta$-carotene in pumpkin flesh, peel, and seed are comparable with those reported in literature in vegetables including pumpkin. Varied amounts of $\beta$-carotene in pumpkin samples were due to several environmental factors (nutrient, water, and soil), age, parts of pumpkin, and species of pumpkin.

\section{Data Availability}

All the data are included within the manuscript.

\section{Conflicts of Interest}

The authors declare that they have no conflicts of interest.

\section{Acknowledgments}

The authors are grateful to the Department of Chemistry, College of Natural and Computational Sciences, Addis Ababa University, Addis Ababa, Ethiopia, for proving laboratory facilities. Mulu Hagos is thankful to Ethiopian Police University, Ethiopia, for sponsoring her study.

\section{References}

[1] A. Hussain, T. Kausar, and A. Din, "Antioxidant and antimicrobial properties of pumpkin (Cucurbita maxima) peel, flesh and seeds powders," Journal of Biology, Agriculture and Healthcare, vol. 11, no. 6, pp. 42-51, 2021.

[2] R. Kwiri, C. Winini, and A. Musengi, "Proximate composition of pumpkin gourd (Cucurbita Pepo) seeds from Zimbabwe," International Journal of Nutrition and Food Sciences, vol. 3, no. 4, pp. 279-283, 2014.

[3] S. H. Koh and S. P. Loh, "In vitro bioaccessibility of $\beta$-carotene in pumpkin and butternut squash subjected to different cooking methods," International Food Research Journal, vol. 25, no. 1, pp. 188-195, 2018.

[4] M. Z. Amin, T. Islam, M. R. Uddin, M. J Uddin, M. M Rahman, and M. A Satter, "Comparative study on nutrient contents in the different parts of indigenous and hybrid varieties of pumpkin (Cucurbita maxima Linn.)," Heliyon, vol. 5, Article ID e02462, 2019.

[5] T. Abrha, Y. Girma, K. Haile, M. Hailu, and M. Hailemariam, "Prevalence and associated factors of clinical manifestations of vitamin a deficiency among preschool children in asgedetsimbla rural district, north Ethiopia, a community based cross sectional study," Archives of Public Health, vol. 74, no. 1, 4 pages, 2016.

[6] N. Zahra, A. Nisa, and F. Arshad, "Comparative study of beta carotene determination by various methods," Biological Bulletin, vol. 2, no. 1, pp. 74-106, 2016.

[7] P. Karnjanawipagul, W. Nittayanuntawech, P. Rojsanga, and L. Suntornsuk, "Analysis of beta-carotene in carrot by spectrophotometry," University Journal of Pharmaceutical Science, vol. 37, no. 1-2, pp. 8-16, 2010.

[8] K. Khairun Nisa and R. M. Ryka Marina Walanda, "Analysis of Beta-carotene from jongi (Dillenia serrata thunb.) as a source of vitamin A," World Journal of Advanced Research and Reviews, vol. 10, no. 2, pp. 184-190, 2021.

[9] S. Aremu and C. Nweze, "Determination of vitamin A content from selected Nigerian fruits using spectrophotometric method," Bangladesh Journal of Scientific and Industrial Research, vol. 52, no. 2, pp. 153-158, 2017.

[10] L. M. J. D. Carvalho, L. D. A. S. M. Smiderle, J. L. V. D. Carvalho, F. D. S. N. Cardoso, and M. G. B. Koblitz, "Assessment of carotenoids in pumpkins after different home cooking conditions," Food Science and Technology Campinas, vol. 34, no. 2, pp. 365-370, 2014.

[11] A. I. O. Barba, M. C. Hurtado, M. C. S. Mata, V. F. Ruiz, and M. L. S. d. Tejada, "Application of a UV-vis detection-HPLC method for a rapid determination of lycopene and $\beta$-carotene in vegetables," Food Chemistry, vol. 95, no. 2, pp. 328-336, 2006.

[12] M. H. Moh, Y. B. Che Man, and B. S. Badlishah, "Quantitative analysis of palm carotene using Fourier transform infrared and near infrared spectroscopy," Journal of the American Oil Chemists' Society, vol. 76, no. 2, pp. 149-254, 1999.

[13] S. Norshazila, J. Irwandi, and R. Othman, "Carotenoid content in different locality of pumpkin (Cucurbita moschata) in Malaysia," International Journal of Pharmacy and Pharmaceutical Sciences, vol. 6, no. 3, pp. 29-32, 2014.

[14] R. Pritwani and P. Mathur, " $\beta$-Carotene content of some commonly consumed vegetables and fruits available in Delhi, India," Journal of Nutrition \& Food Sciences, vol. 7, no. 625, 2017.

[15] M. Kreck, P. Kuerbel, M. Ludwig, P. J. Paschold, and H. Dietrich, "Identification and quantification of carotenoid in pumpkin cultivars (Cucurbita maxima L.) and their juices by liquid chromatography with ultraviolet-diode array detection," Journal of Applied and Food Quality, vol. 80, pp. 93-99, 2006.

[16] N. Quijano-ortega, C. A. Fuenmayor, C. Zuluaga-dominguez et al., "FTIR-ATR spectroscopy combined with multivariate regression modeling as a preliminary approach for carotenoids determination in Cucurbita spp," Applied Sciences, vol. 10 , no. 11, p. 3722, 2020.

[17] K. Deák, T. Szigedi, and Z. Pékl, "Carotenoid determination in tomato juice using near infrared spectroscopy," International Agrophysics, vol. 29, pp. 275-282, 2015. 
[18] A. Senoretta and J. H. Sumathy, "Beta carotene analysis from vegetables using FTIR," Unique Journal of Ayurvedic and Herbal Medicines, vol. 4, no. 5, pp. 15-18, 2016.

[19] S. I. Riyanto, S. Martono, and A. Rohman, "The employment of FTIR spectroscopy and chemometrics for authentication of pumpkin seed oil from sesame oil," Food Research, vol. 4, no. 1 , pp. 42-48, 2020.

[20] R. Nokkaew, V. Punsuvon, T. Inagaki, and S. Tsuchikawa, "Determination of carotenoids and dobi content in crude palm oil by spectroscopy techniques: comparison of Raman and FT-NIR spectroscopy," International Journal of Geomate, vol. 16, no. 55, pp. 92-98, 2019.

[21] P. Rungpichayapichet, B. Mahayothee, and P. Khuwijitjaru, "Non-destructive determination of b-carotene content in mango by near-infrared spectroscopy compared with colorimetric measurements," Journal of Food Composition and Analysis, vol. 38, no. 10, 2015.

[22] A. K. Biswas, J. Sahoo, and M. K. Chatli, "A simple UV-Vis spectrophotometric method for determination of $\beta$-carotene content in raw carrot, sweet potato and supplemented chicken meat nuggets," Lebensmittel-Wissenschaft und-TechnologieFood Science and Technology, vol. 44, no. 8, pp. 1809-1813, 2011.

[23] M. Baranska, W. Schütze, and H. Schulz, "Determination of lycopene and $\beta$-carotene content in tomato fruits and related products: comparison of FT-Raman, ATR-IR, and NIR spectroscopy," Analytical Chemistry, vol. 78, no. 24, pp. 8456-8461, 2006.

[24] D. Martínez-Valdivieso, R. Font, M. T. Blanco-Díaz et al., "Application of near-infrared reflectance spectroscopy for predicting carotenoid content in summer squash fruit," Computers and Electronics in Agriculture-Journals, vol. 108, pp. 71-79, 2014.

[25] T. De Nardo, C. Shiroma-Kian, Y. Halim, D. Francis, and L. E. Rodriguez-Saona, "Rapid and simultaneous determination of lycopene and $\beta$-carotene contents in tomato juice by infrared spectroscopy," Journal of Agricultural and Food Chemistry, vol. 57, no. 4, pp. 1105-1112, 2009.

[26] M. Careri, L. Elviri, and A. Mangia, "Liquid chromatographyelectrospray mass spectrometry of $\beta$-carotene and xanthophylls," Journal of Chromatography A, vol. 854, no. 1-2, pp. 233-244, 1999.

[27] M. Y. Kim, E. J. Kim, Y.-N. Kim, C. Choi, and B.-H. Lee, "Comparison of the chemical compositions and nutritive values of various pumpkin (Cucurbitaceae) species and parts," Nutrition Research and Practice, vol. 6, no. 1, pp. 21-27, 2012.

[28] J. Pongjanta, A. Naulbunrang, S. Kawngdang, T. Manon, and T. Thepjaikat, "Utilization of pumpkin powder in bakery products," Songklanakarin Journal of Science and Technology, vol. 28, no. 1, pp. 71-79, 2006.

[29] I. Nakazibwe, E. A. Olet, and G. Kagoro-Rugunda, "Nutritional physico-chemical composition of pumpkin pulp for value addition: case of selected cultivars grown in Uganda," African Journal of Food Science, vol. 14, no. 8, pp. 233-243, 2020.

[30] S. Javeria, T. Masud, S. Sammi et al., "Comparative study for the extraction of $\beta$-carotene in different vegetables," Pakistan Journal of Nutrition, vol. 12, no. 11, pp. 983-989, 2013. 